BLS 32, No 1 2006. DOI: http://dx.doi.org/10.3765/bls.v32i1.3440 (published by the Berkeley Linguistics Society and the Linguistic Society of America)

\title{
Wh-Conditionals in Vietnamese and Chinese: Against Unselective Binding
}

\author{
BENJAMIN BRUENING and THUAN TRAN \\ University of Delaware
}

\section{Introduction}

This paper examines a type of conditional construction in which wh-words appear in pairs, one in each clause of the conditional, as illustrated in Mandarin Chinese in (1), from Cheng and Huang (1996):

(1) Shei xian lai, shei jiu xian chi. who first come who then first eat 'If X comes first, $\mathrm{X}$ eats first.'

Cheng and Huang (1996) refer to these conditionals as 'bare conditionals' because they usually lack the word 'if'. However, this is not a general property of these conditionals crosslinguistically (or even in Chinese; see Lin 1996); we therefore refer to them as wh-conditionals. The defining property of these conditionals is that they must contain a matched pair of wh-phrases, one in the antecedent and one in the consequent, as illustrated in (1). The two wh-phrases are interpreted as the same variable, as indicated in the English translation.

\subsection{The Unselective Binding Analysis}

Cheng and Huang (1996) argue that this type of conditional requires an analysis in which the wh-words are open predicates with a variable that comes to be bound by a null (or sometimes overt) adverb of quantification, as illustrated below. If there is no overt adverb of quantification, the variables are bound by a covert necessity operator (NEC), which is essentially a universal quantifier:

a.

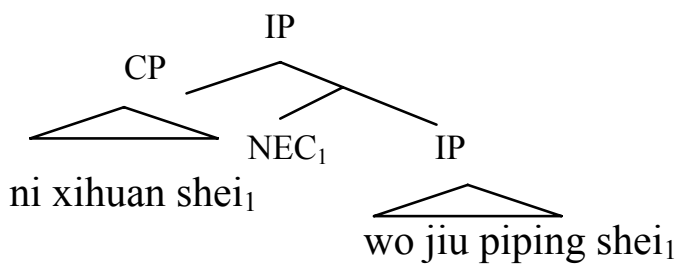




\section{b. $\forall \mathrm{x}[$ you like person $(\mathrm{x})] \rightarrow[\mathrm{I}$ criticize person $(\mathrm{x})]$}

The binding of the conditional operator is unselective. It is possible to have multiple pairs of wh-phrases:

(3) Shei yan shei, shei jiu xiang shei. who play who who then resemble who 'If X plays the role of $\mathrm{Y}$, then $\mathrm{X}$ will resemble $\mathrm{Y}$.'

(Cheng and Huang 1996)

Cheng and Huang (1996) argue that because wh-conditionals must be analyzed as unselective binding, recent attempts to do without unselective binding (e.g. Heim 1990, von Fintel 1995) are doomed to failure. If Cheng and Huang are right, unselective binding must be available in the grammars of natural languages.

\subsection{Our Claim}

We argue that the unselective binding theory is actually not the best account of wh-conditionals. First, we outline several insurmountable problems for the unselective binding theory. Then we bring in data from Vietnamese which point to an alternative account, one that involves sideward movement (Nunes 2004). Basically, the two wh-phrases form a chain, with both copies pronounced due to a lack of c-command. This theory solves the problems that beset the unselective binding account; it also means that wh-phrases as indefinites are quantifiers, not open predicates, and there is no need for unselective binding.

\section{Against Unselective Binding}

\subsection{A Problem with Licensing}

In Chinese, wh-phrases can be used as indefinites; however, in this use they are like negative polarity items and require some kind of licensor. Licensors in Chinese include non-factive verbs like 'think' (4a), modals (4b), negation (5a), conditional operators $(5 \mathrm{~b})$, and yes/no question operators $(5 \mathrm{c})$ :

a. Wo yiwei ni fandui/kandao shenme (dongxi). I think you oppose/see what thing 'I thought you were opposed to/saw something.'

b. Wo mingtian hui qu mai ge shenme dongxi song ta de. I tomorrow will go buy $\mathrm{Cl}$ what thing give him Prt 'I will go to buy something for him.'

(5) a. Ta bu xihuan shenme.

he not like what 'He doesn't like anything.' 


\section{Wh-Conditionals: Against Unselective Binding}

b. Ruguo ni kandao shei, qing jiao ta lai jian wo. if you see who please tell him come see me 'If you see someone, please tell him/her to come see me.'

(Cheng and Huang 1996)

c. Ta xihuan shenme ma?

he like what $\mathrm{Q}$

'Does he like anything?'

In the unselective binding theory, the two wh-phrases in a wh-conditional are indefinites. As such, they must be licensed in Chinese. The problem is that the second clause of a conditional is not a licensing environment. The first wh-phrase is licensed, as the antecedent clause of a conditional is a licensing environment (see $5 \mathrm{~b}$ ), but the consequent clause of a conditional is not a licensing environment:

$$
\begin{aligned}
& \text { *Ruguo ni lai (tongchang) shei jiu hui hen gaoxing. } \\
& \text { if you come (usually) who then will very happy }
\end{aligned}
$$

'If you come, someone will (usually) be very happy.'

(Lin 1998)

A wh-phrase is ungrammatical here as an indefinite, even when there is an adverb of quantification that could bind it as a variable. It is therefore completely mysterious on the unselective binding approach how a wh-indefinite could appear in the second clause of a conditional.

\subsection{A Contrast between Lexical and Wh-Indefinites}

In the unselective binding theory, wh-phrases used as indefinites are open predicates. They are just like lexical indefinites in the classical Kamp/Heim analysis of quantificational variability (Kamp 1981, Heim 1982). Therefore, on the unselective binding theory, one would expect that any indefinite could appear in pairs in a wh-conditional. This is not correct, however; only wh-phrases can: ${ }^{1}$

a. *You ren xian jinlai, you ren xian chi. there's person first come there's person first eat 'If a person first comes, a person $_{1}$ first eats.'

b. *Ni xihuan ren, wo jiu piping ren. you like person I then criticize person 'If you like a person 1 , I criticize a person 1 .'

\footnotetext{
${ }^{1}$ Chinese examples without a citation come from informants consulted in the writing of this paper: Yaping Tsai, Chun-chieh Hsu, Perng Wang Adams, and Elenna Tseng - all from Taiwan.
} 
Benjamin Bruening and Thuan Tran

On Cheng and Huang's assumptions, this disparity is completely unexpected. The sentence in (7b), for instance, should permit unselective binding as $\forall x$ [ you like person $(x)] \rightarrow[$ I criticize person $(x)]$.

\subsection{The Novelty Condition and Condition $\mathbf{C}$}

Chierchia (2000), citing Satoshi Tomioka, points out that Cheng and Huang's theory also runs into a problem with the Novelty Condition of Heim (1982), which says that an indefinite NP must not have the same index as any NP preceding it. The problem is that wh-phrases in Chinese are indefinites, and in every context but wh-conditionals they must introduce a new discourse referent. Just in whconditionals, however, the second wh-phrase does not introduce a new referent, and in fact must refer back to the same referent as the first wh-phrase.

Chierchia attempts to fix this problem by adopting a Dynamic Semantics theory of reference, in which indefinites are existential quantifiers. For unselective binding to work, the existential quantifier must be stripped off through the operation of Existential Disclosure (Dekker 1993). The details of this theory are unimportant here; the point to note is that in this theory there is no Novelty Condition. Its effects derive from the fact that indefinites are usually existential quantifiers, which by definition introduce new discourse referents. When the existential quantifier has been removed, however, they do not need to, explaining the co-variation in wh-conditionals.

Chierchia's theory does explain the lack of Novelty Condition effects in whconditionals, but it runs into the same problem with the contrast between lexical and wh-indefinites as Cheng and Huang's. In fact, this problem is a general one for any theory that invokes unselective binding.

Chierchia does attempt to solve this problem by hypothesizing that whindefinites can occur in pairs in conditionals because they are pronouns. Lexical indefinites are ruled out by Condition $\mathrm{C}$, being $\mathrm{R}$-expressions. Because neither lexical indefinite in a wh-conditional c-commands the other, Chierchia argues that coindexing them would violate Condition $\mathrm{C}$ on a revised definition of binding:

(8) An argument $\mathrm{A}$ binds $\mathrm{B}$ iff $\mathrm{A}$ and $\mathrm{B}$ are coindexed and either (i) $\mathrm{A}$ c-commands B, or (ii) A is coindexed with a Q-adverb that c-commands B. (Chierchia 2000:27)

In order to rule out lexical indefinites and permit wh-indefinites in whconditionals, then, Chierchia has to make two non-standard hypotheses: he has to revise the definition of binding to include binding mediated by a quantificational adverb, and he has to claim that wh-words are pronouns, not R-expressions.

The problem with this theory is that wh-phrases in Chinese are subject to Condition C and hence must be R-expressions. This is illustrated in (9), where shei is in a Strong Crossover configuration (actually, its wh-in-situ counterpart): 


\section{Wh-Conditionals: Against Unselective Binding}

(9)
*Ta ${ }_{1}$ shuo shei ${ }_{1}$ xihuan wo meimei?
he say who like my sister
'Who ${ }_{1}$ did he ${ }_{1}$ say likes my sister?'

Chierchia could argue that wh-phrases in questions are R-expressions, but as indefinites are pronouns. This will not work either, though, since wh-indefinites may not be c-commanded even in wh-conditionals:

a. Shei yaoshi shuo ta/*shei xihuan wo meimei, wo jiu zou shei. who if say he/*who like mysister I then hit who 'If X says that he likes my sister, I hit X.'

b. Shei yaoshi jinlaibu qiaomen, wo jiu gaosu shei ta/*shei who if enter Neg knock I then tell who he/*who hen luman. very rude 'If X enters without knocking, I tell X that he's very rude.'

These facts clearly show that wh-phrases generally, and wh-indefinites in whconditionals in particular, are in fact subject to Condition C. They are therefore Rexpressions, not pronouns. ${ }^{2}$

Chierchia's suggestion, then, is certainly not correct, and thus he has no way to distinguish between lexical indefinites and wh-indefinites. In fact, this is a problem that will beset any account of wh-conditionals involving unselective binding.

\section{Wh-Conditionals in Vietnamese}

The data we are about to introduce from Vietnamese become particularly important given a related problem for the unselective binding account. This is that a whphrase can only take another wh-phrase as its antecedent in a wh-conditional. The indefinite 'a person' is semantically identical to 'who' in the unselective binding theory, so one would expect the following example to be grammatical, contrary to fact:

*You ren xian jinlai, shei xian chi. there's person first come who first eat 'If a person ${ }_{1}$ comes first, who ${ }_{1}$ eats first.'

Cheng and Huang (1996) attempt to account for this restriction with the constraint below:

${ }^{2}$ Compare English one, which Chierchia argues to be similar to repeated wh-indefinites in Chinese. This element most certainly is a pronoun, and it can be c-commanded:

(i) If one wants to be happy, one should tell one's parents to leave one alone. 


\section{Benjamin Bruening and Thuan Tran}

(12) Cheng and Huang (1996): In a tripartite structure of quantification Q [A] $[B],\left[X_{1}, X_{2}, \ldots X_{n}\right]($ where $n \geq 1)$ are variables in A. For every variable in $\mathrm{A}$, there must be an identical variable in $\mathrm{B}$.

That is, a wh-phrase can only be bound by an adverb of quantification that binds an identical wh-phrase. (Note that this does not rule out identical lexical indefinites; also note that it cannot account for the grammatical examples involving pronouns in 10a-b.) However, in Vietnamese wh-conditionals, the anaphoric element in the consequent clause is not a matching wh-phrase:

a. Ai làm, nấy chịu. who do NAY bear 'If $\mathrm{X}$ does (something), $\mathrm{X}$ bears responsibility (for it).'

b. *Ai làm, ai chịu. who do who bear 'If X does (something), X bears responsibility (for it).'

One could of course claim that the Vietnamese conditional in (13a) is not equivalent to the Chinese wh-conditional. However, this type of conditional in Vietnamese has all of the properties of wh-conditionals in Chinese. In particular, it is impossible to analyze the element $n \hat{a} y$ as some type of e-type pronoun; this is the same argument Cheng and Huang gave to show that unselective binding is necessary for Chinese wh-conditionals. Following the logic that Cheng and Huang use to argue that wh-conditionals in Chinese must involve unselective binding, we must conclude that these conditionals in Vietnamese also involve unselective binding, directly contradicting the principle in (12).

First, the element nấy has a very limited distribution. It only appears in this one context, in the consequent clause of a conditional that contains a wh-phrase in the antecedent (and one other context, illustrated below). E-type pronouns typically have the form and distribution of pronouns or definite descriptions. The element nấy cannot appear by itself, unlike a pronoun or definite description:

*Nấy/người ấy mới đến lúc tám giờ. NAY/person that just arrive at eight hour 'That person just arrived at 8 o'clock.'

E-type pronouns do exist in Vietnamese and can be used in conditionals, as shown in the following examples: 


\section{Wh-Conditionals: Against Unselective Binding}

(15) Ai làm xong bài tập người ấy/[e] có thể về trước giờ who do finish exercise person that/[e] can go home before hour qui định.

rule

'Anyone who finishes the exercise can leave earlier than they should.'

Nếu anh thấy đứa nào ném đá anh phạt nó cho tôi. if you see $\mathrm{Cl}$ which throw stone you punish he/she give I 'If you see any kid throw stones, please punish him/her for me.'

As shown in the data above, e-type pronouns in Vietnamese can be definite descriptions, null pronouns, or overt pronouns. E-type pronouns can also be used to pick up reference cross-sententially, but nấy cannot:
A: Ai nộp bài sớm [e] được thêm năm điểm. who hand.in paper early [e] receive addition five mark 'Whoever hands in their paper early will get five more marks.'

B: Nhưng nếu *nấy/người ấy làm sai thì sao? but if NAY/person that do wrong then how 'But what happens if they do it wrong?'

\section{A: Nếu *nấy/người ấy làm sai thì bị bớt sáu điểm. if NAY/person that do wrong then suffer extract six mark 'If they do it wrong, they will have six marks taken out of the total.'}

If nấy were an e-type pronoun, we would expect it to be able to appear in such a context. Instead, it shows the much more limited distribution of the second whphrase in a Chinese wh-conditional.

In addition, nấy acts just like the wh-phrases in Chinese wh-conditionals in that it cannot occur more than once:
Anh thích ai, tôi nói với nấy/người ấy là anh ghét you like who, I say with NAY/person that you hate *nấy/người ấy/họ.
$\mathrm{NAY} /$ person that/they
'If you like X, then I tell X that you hate X.'

Above this was used to argue that wh-phrases are subject to Condition $\mathrm{C}$, but it also means that nấy, like the second wh-phrase in a Chinese wh-conditional, could not be an e-type pronoun, since e-type pronouns (including those that have the form of definite descriptions) are not subject to Condition C.

Cheng and Huang argued that, because the second element in a whconditional could not be analyzed as an e-type pronoun, the only alternative is an 
Benjamin Bruening and Thuan Tran

unselective binding analysis. That seems to be the only alternative for Vietnamese, too, but in the preceding section we saw numerous problems with the unselective binding analysis as well.

We suggest that Vietnamese holds a clue to the proper analysis of whconditionals. In particular, it cannot be crucial to the interpretation of whconditionals that the two clauses of the conditional contain matching NPs that are independently open predicates suitable for unselective binding. The element nấy is not such an indefinite, and it does not match its antecedent. Above we mentioned that nấy does appear in one other environment. In subject position, it appears as a constituent with a wh-phrase. The two together are interpreted (apparently) as a universal quantifier:

$$
\begin{aligned}
& \text { Ai nấy vui vẻ. } \\
& \text { who NAY happy } \\
& \text { 'Everyone is happy.' }
\end{aligned}
$$

Tran (2005) analyzes nấy in this construction as a demonstrative with the role of a universal quantifier. In order to unify this use with wh-conditionals, however, and because this element can only appear in subject position, we suggest that it is actually an existential quantifier. Universal quantification comes from a null adverb of quantification quantifying over situations, exactly as in a whconditional (see below). Just when ai nấy appears in subject position, it can be parsed as the restrictive clause of the adverb of quantification:

$$
\begin{aligned}
& \forall \mathrm{s}[\exists \mathrm{x} \cdot \mathrm{x} \text { is a person in } \mathrm{s}] \\
& \quad \rightarrow\left[\exists \mathrm{s}^{\prime} \cdot \mathrm{s} \leq \mathrm{s}^{\prime} \& \text { the person identical to } \mathrm{x} \text { is happy in } \mathrm{s}^{\prime}\right]
\end{aligned}
$$

(We assume that subjects are generated internal to VP, so that the trace of the subject serves as the variable in the matrix; see below for the interpretation of traces.) To paraphrase, the sentence in (19) actually means, 'Every situation where there is a person is a situation where that person is happy.'

In this analysis, ai nấy is an existential quantifier, and the apparent universal quantification comes from a null operator quantifying over situations.

\subsection{A Sideward Movement Analysis of Wh-Conditionals}

We suggest that, contrary to appearances, nấy forms a constituent with the whphrase in a wh-conditional, too, and the two together have the interpretation given above, as an existential quantifier. The reason they appear to be separate is that this constituent moves from one clause of the conditional to the other; because neither link in the chain c-commands the other, both links have to be spelled out, one as $a i$ and the other as nấy. Thus, we suggest the syntactic representation in (21b) for the wh-conditional in (21a): 


\section{Wh-Conditionals: Against Unselective Binding}

a. Ai làm, nấy chịu. who do NAY suffer 'You are responsible for what you do.'

b.

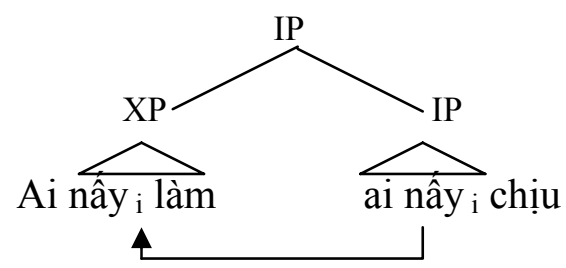

The type of movement that we are suggesting here is Nunes's (2004) Sideward Movement: the computational system copies a given constituent of a syntactic object $\mathrm{K}$ and merges it with a syntactic object $\mathrm{L}$, independently assembled and unconnected to $\mathrm{K}$ at the time of movement.

How this theory applies to the sentence in (21) is as follows, assuming that the Numeration of (22a) is that in (22b).
a. ai làm, nấy chịu.
b. $\mathrm{N}=\left\{\operatorname{làm}_{1}\right.$ 'do', ai-nấy ${ }_{1}$ 'everyone', chịu ${ }_{1}$ 'bear' $\}$

First, we derive the matrix clause by merging the quantified expression with the verb chịu 'bear': [IP ai-nấy chịu]. Second, we construct the adjoined clause by making a copy of [ai-nấy] and merging that copy as the argument of the verb 'do': [XP ai-nấy làm]. Third, we merge this clause with the main clause previously formed: [IP [XP ai-nấy làm] [IP ai-nấy chịu]].

We suggest that in such cases of sideward movement, where some link of a chain is not c-commanded by another link in the chain, that link must be spelled out. This is why the first link is spelled out as $a i$ and the second link is spelled out as $n \hat{a} y$ (strikeouts indicate lack of pronunciation):

$$
\begin{aligned}
& \text { [ai-nấy } \left.]_{i} \text { làm [ai-nấy }\right]_{i} \text { chịu. } \\
& \text { who do NAY bear }
\end{aligned}
$$

\subsection{The Interpretation of Wh-Conditionals}

In our analysis, nấy in the consequent clause is the trace of the full phrase (which is only partially pronounced) in the antecedent clause. In order to interpret this, we adopt Fox's $(1999,2002)$ rule for interpreting traces:

a. Variable Insertion (Det) Pred $\rightarrow($ Det $)[\operatorname{Pred} \lambda \mathrm{y}(\mathrm{y}=\mathrm{x})]$

b. Determiner Replacement: (Det) $[\operatorname{Pred} \lambda \mathrm{y}(\mathrm{y}=\mathrm{x})] \rightarrow$ the $[\operatorname{Pred} \lambda \mathrm{y}(\mathrm{y}=\mathrm{x})]$

For instance, after wh-movement applies to a question like Which boy did Mary visit hich boy? (where strikeouts indicate lack of pronunciation again), the lower 
copy (the trace) is converted to Which boy $\lambda x$ [Mary visited the boy $\boldsymbol{x}$ ].

We also adopt Kratzer's (1989) and Heim's (1990) situation semantics for conditionals. Accordingly, the Vietnamese wh-conditional in (21), repeated below, is interpreted as in (25):

$$
\begin{aligned}
& \text { (21) Ai làm, nấy chịu. } \\
& \text { who do NAY suffer } \\
& \text { 'If X does (it), X suffers (for it).' } \\
& \text { (25) } \quad \forall \mathrm{s}[\exists \mathrm{x} . \mathrm{x} \text { is a person \& } \mathrm{x} \text { does in } \mathrm{s}] \\
& \rightarrow[\exists \mathrm{s} \text { '. } \mathrm{s} \leq \mathrm{s} \text { ' \& the person } \mathrm{x} \text { suffers in s'] }
\end{aligned}
$$

The representation in (25) is exactly what sentence (21) means.

\section{Chinese Wh-Conditionals from the Vietnamese Perspective}

We propose that Chinese wh-conditionals employ sideward movement just like in our analysis of Vietnamese above. However, Chinese is unlike Vietnamese in that each copy is fully pronounced:

a. Shei xian lai, shei jiu xian chi. who first come who then first eat 'If X comes first, $\mathrm{X}$ eats first.'

b.

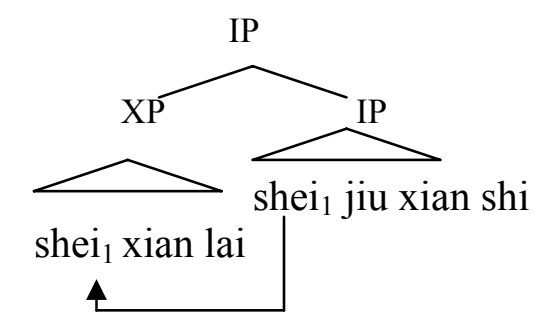

We suggest that this follows from the fact that the Chinese existential quantifier is morphologically simplex, unlike the Vietnamese existential quantifier, which is complex.

Chinese wh-conditionals in our theory are interpreted the same way as Vietnamese wh-conditionals - that is, through situation semantics and the Trace Conversion Rule. The sentence in (27) is then interpreted as in (28).

$$
\begin{aligned}
& \forall \mathrm{s}[\exists \mathrm{x} . \mathrm{x} \text { is a person \& } \mathrm{x} \text { comes first in } \mathrm{s}] \\
& \quad \rightarrow\left[\exists \mathrm{s}^{\prime} . \mathrm{s} \leq \mathrm{s}^{\prime} \& \text { the person } \mathrm{x} \text { eats first in } \mathrm{s}^{\prime}\right]
\end{aligned}
$$

This theory captures the semantics of wh-conditionals, but it does so without unselective binding and without e-type pronouns. The second wh-phrase is the trace of the first. 


\section{Wh-Conditionals: Against Unselective Binding}

\section{Advantages of the Theory and Conclusion}

The movement theory outlined above resolves the problems that beset the unselective binding theory. First, the licensing conditions on wh-indefinites are met in Chinese, because one member of the chain (the one in the antecedent clause) does occur in a licensing environment. Second, there is no issue with the novelty condition, again because the two wh-phrases are related via movement: they are the same syntactic element. Traces do not introduce new discourse referents.

As for the contrast between wh-indefinites and lexical indefinites like 'a person', we suggest that lexical indefinites are unable to undergo sideward movement. Unfortunately, we do not have a complete explanation for this restriction yet, but it is true crosslinguistically that only wh-phrases occur in wh-conditionals (besides Chinese and Vietnamese, Indonesian and Passamaquoddy, that we know of, have wh-conditionals). It seems to be the case that sideward movement is limited to specific kinds of quantifiers, specifically wh-quantifiers. We admit that our explanation here is incomplete, but we believe a natural explanation is much more likely to be found in restrictions on movement than in ad hoc restrictions on unselective binding as were proposed by Cheng and Huang (1996) and Chierchia (2000). We know that wh-phrases undergo special kinds of movement that other phrases do not; in the unselective binding theory, however, all indefinites are treated identically, and they behave the same as far as quantificational variability is concerned.

Finally, the broader implication of this theory is that unselective binding is unnecessary. There is no need to posit unselective binding in the grammars of natural languages; indefinites are always existential quantifiers, and the apparent effects of quantificational variability can be captured through situation semantics and other mechanisms (see Heim 1990, von Fintel 1995).

\section{References}

Cheng, Lisa L.-S., and C.-T. James Huang. 1996. Two Types of Donkey Sentences. Natural Language Semantics 4:121-163.

Chierchia, Gennaro. 2000. Chinese Conditionals and the Theory of Conditionals. Journal of East Asian Linguistics 9:1-54.

Dekker, Paul. 1993. Existential Disclosure. Linguistics and Philosophy 16:561-587.

Fox, Danny. 1999. Reconstruction, Binding Theory, and the Interpretation of Chains. Linguistic Inquiry 30:157-196.

Fox, Danny. 2002. Antecedent Contained Deletion and the Copy Theory of Movement. Linguistic Inquiry 33:63-96.

Heim, Irene. 1982. The Semantics of Definite and Indefinite Noun Phrases. Ph.D. diss., University of Massachusetts, Amherst.

Heim, Irene. 1990. E-Type Pronouns and Donkey Anaphora. Linguistics and Philosophy 13:137-177. 
Kratzer, Angelika. 1989. An Investigation of the Lumps of Thought. Linguistics and Philosophy 12:607-653.

Li, Yen-Hui Audrey. 1992. Indefinite Wh in Mandarin Chinese. Journal of East Asian Linguistics 1:125-155.

Li, Yen-Hui Audrey. 1996. Definite and Indefinite Existential Constructions. Studies in the Linguistic Sciences 26:175-191.

Lin, Jo-Wang. 1996. Polarity Licensing and Wh-Phrase Quantification in Chinese. Ph.D. diss., University of Massachusetts, Amherst.

Lin, Jo-Wang. 1998. Distributivity in Chinese and Its Implications. Natural Language Semantics 6:201-243.

Nunes, Jairo. 2004. Linearization of Chains and Sideward Movement. Cambridge, MA: MIT Press.

Thuan, Tran. 2005. Wh-Conditionals in Vietnamese. Paper presented at Theoretical East Asian Linguistics, Harvard University.

Von Fintel, Kai. 1995. A Minimal Theory of Adverbial Quantification. In Barbara Partee and Hans Kamp, eds., Context Dependence in the Analysis of Linguistic Meaning: Proceedings of the Workshops in Prague. IMS Stuttgart Working Papers, 153-193.

Benjamin Bruening

Department of Linguistics

University of Delaware

42 E. Delaware Avenue

Newark, DE 19716

bruening@udel.edu
Thuan Tran

Department of Linguistics

University of Delaware

42 E. Delaware Avenue

Newark, DE 19716

tthuan@udel.edu 